\title{
Exploring the relationship between college students' writing anxiety and the pedagogical use of online resources
}

Xiaodong Zhang(D)

\author{
Correspondence: zxdman588@ \\ gmail.com \\ School of English and International \\ Studies, Beijing Foreign Studies \\ University, Beijing, China
}

\begin{abstract}
This study reports on how the use of online resources based on systemic functional linguistics (SFL) impacted college students' emotional alignment with writing practices. Through qualitative analyses of in-class discussions, students' interviews and reflections, as well as their written pieces gathered in a Chinese university, the case study shows that the students were able to overcome their fears with writing construction associated with their dearth of effective knowledge, albeit through a zigzag trajectory. More importantly, they could utilize the knowledge imparted through online resources, actively and confidently participating in unpacking written discourse and effectively constructing their own writing. The study concludes the importance of harnessing online resources that are effectively designed and linguistically grounded. It sheds light on the role of SFL as a linguistic technique to alleviate students' anxieties while offering them knowledge needed for effective written communication.
\end{abstract}

Keywords: Writing anxiety, Functional linguistics, Writing confidence, Online resources, College writing

\section{Introduction}

Writing requires writers to harness appropriate lexicon and grammar to organize mental meanings and construct the contents to be delivered (Hyland, 2007). As a result, the intricacy of writing often poses challenges for student writers, causing anxiety (i.e., different levels of emotional discomfort, such as apprehension and distress) associated with writing construction (Huerta, Goodson, Beigi, \& Chlup, 2017). While this type of anxiety is transient or situation-specific, since it arises only when students are stimulated with writing tasks (Zhang \& Rahimi, 2014), it is detrimental to students' successful performance of written communication (e.g., Bayat, 2014). Fortunately, writing anxiety can be mitigated by supplementing the communication skills that students need to construct writing, which means "the importance of teacher support" in this regard (Horwitz, 2001, p. 121). That is, teachers can alleviate students' anxiety through teaching effective writing knowledge.

Effective written communication does not only involve sentential accuracy. It also concerns the use of linguistically or culturally appropriate language features when constructing writing (Halliday \& Matthiessen, 2004). For example, in the process of

(c) The Author(s). 2019 Open Access This article is distributed under the terms of the Creative Commons Attribution 4.0 International License (http://creativecommons.org/licenses/by/4.0/), which permits unrestricted use, distribution, and reproduction in any medium, provided you give appropriate credit to the original author(s) and the source, provide a link to the Creative Commons license, and indicate if changes were made. 
academic communication, the authorial evaluative stance has to be appropriately projected for a specific genre (e.g., expository writing prefers an implicit stance), and a fluent flow of information flow, such as using conjunctive words to create textual connections or explicit logical relationships (Martin \& David, 2008; Mitchell \& Pessoa, 2017). Nevertheless, in many existing contexts of writing instruction, sentential accuracy seems to dominate English teaching curricula (Zhang, 2017). In this constrained teaching and learning milieu, students understandably become anxious about their academic literacy (e.g., writing) as they only attend to the structural grammar, lacking the additional knowledge needed to produce effective writing beyond the sentence level. Furthermore, although using textbooks is a crucial channel for students to develop their knowledge repertoires, the content used in the writing classroom often fails to help teachers provide sufficient information for effective academic communication (You, 2004). This suggests that the supplementation of useful resources, such as online educational resources, can ameliorate classroom teaching and provide students with the necessary knowledge, thereby reducing their anxiety (Taffs \& Holt, 2013).

Overall, there is the close relationship between students' writing anxiety and writing knowledge; it is also promising to use the contents of materials sourced online to enhance their knowledge repertoires in the classroom where textbooks are limited in contents. However, no such research has been conducted so far. Hence, it is worthwhile to explore how students' writing anxiety could be mitigated while learning about writing knowledge through online resources. The purpose of this study attempts to shed light on how an appropriate design and delivery of pedagogical resources affects students' writing anxiety.

\section{Literature review}

\section{Students' writing anxiety}

Indeed, as a specific type of anxiety, writing anxiety differs from personal trait-related anxiety, "a relatively stable personality characteristic" (Horwitz, 2001, p. 113), as it is situation-specific anxiety that occurs only in specific situations (i.e., it occurs right before a writing task). Following this line, recent research on students' language learning anxiety demonstrated similar findings, which are ubiquitous in the field of the speaking classroom although limited in the writing classroom (e.g., Bayat, 2014). That is, there was a negative linear relationship between students' anxiety and their performance. In other words, the higher the level of the students' anxiety, the worse was their writing performance in that they lacked confidence in constructing writing. For example, Huerta et al. (2017), based on a qualitative analysis of 174 students' surveys collected from one writing class and an out-of-class workshop in an American university, showed that students' anxiety was correlated with their efficacy in regulating their writing. Similarly, using correlation analysis, Cheng's (2002) study also found that college English students in Taiwan exhibited a negative linear relationship between their confidence in regulating writing and anxiety. To boost students' writing confidence and alleviate their anxiety, Cheng suggested developing students' effective writing knowledge.

Nevertheless, as Huerta et al. (2017) also pointed out, empirical studies on affording students' confidence and lowering their anxiety are still limited; as such, they called for "specific productivity strategies" (p. 727). Among the few studies that made intervention 
attempts, using an experimental study, Bayat (2014) explored how 10 weeks of process writing (prewriting, drafting, revising, and publishing) impacted first-year college students in a Turkish university. Through a mixed analysis of students' surveys and writing, Byat showed that process writing positively reduced students' writing anxiety, which was because the teacher's mediation offered students' efficacy in constructing writing as errors are "evaluated and corrected as soon as they emerge in the writing process" (p. 1138). This study illustrates the role of teacher support in reducing students' anxiety related to the writing knowledge they need for writing. However, as Hyland (2007) pointed out, while process-based mediation allows for the space for students' writing creation and freedom and grammar correction, it ignores how linguistic resources beyond grammar figure in writing (i.e., contextually appropriate linguistic resources). Hyland (2007) further noted, "there is an urgent need for more theoretically robust, linguistically informed, and research-grounded text descriptions to bridge the gap between home and school writing and prepare learners for their futures" (p. 149).

In sum, there is a need for a combination of process teaching and context-based teaching in the writing classroom to maximally benefit students' writing knowledge and alleviate their anxiety. Halliday and Matthiessen's (2004) writing pedagogy, which is based on systemic functional linguistics (SFL), seems more than appropriate, in that it includes process-based teaching and linguistic knowledge beyond grammar, as discussed below (Martin \& David, 2008).

\section{SFL-based teaching of written communication}

Like process-based writing, the SFL-based writing curriculum emphasizes a writing process that features teacher mediation and offers students space to revisit their essay content or guide them to attend to linguistic resources (Achugar \& Carpenter, 2012; Halliday \& Matthiessen, 2004; Schleppegrell, 2007). More importantly, SFL emphasizes the triadic relationship among context, content, and linguistic resources beyond language accuracy (Martin \& David, 2008; see also Fig. 1 below).

In the process of shuffling from context to meaning construction (i.e., content construction), SFL highlights its own lexico-grammar (i.e., vocabulary and grammar) to explain the choice of linguistic resources within each genre (Schleppegrell, 2007). That is, in addition to its similar part in traditional grammar (i.e., structural accuracy), SFL-based codes particularly illuminate how contextually appropriate lexico-grammar participates in constructing meaning/content at a discourse level (see Halliday \& Matthiessen, 2004 for details).

One component of writing content is ideational meaning, representing language users' inside and outside experience (roughly literal content of discourse communication and logical relationship between the content). Ideational meaning is a meaning constructed responding to the context of situational variable-field, which is concerned with what the discourse is about. At the ideational meaning level, its key codes include participant and process, explaining features of noun phrases and verb phrases (e.g., in expository writing the use of academic lexicon and nominalization instead of spoken language, avoidance of personal mental processes, such as I think). Interpersonal meaning is about enacting social relationships related to writing. It is a content component constructed in response to the context of situational variable-tenor, which identifies 


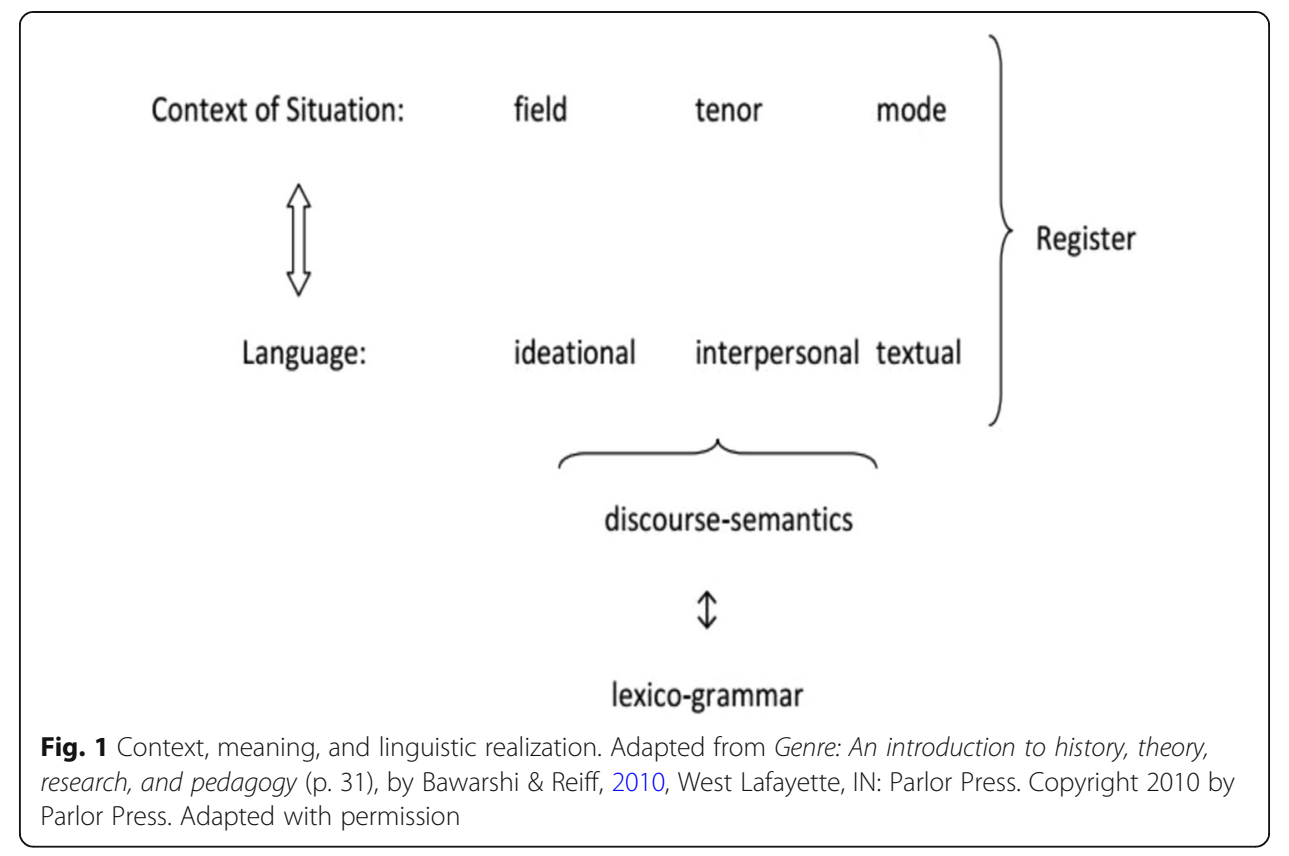

the interpersonal relationships and evaluative stance between the discourse participants. At the interpersonal level, codes include attitude (authorial attitude), graduation (the strength of information), and engagement (the source and certainty of information) to explain the interpersonal meaning embedded in academic writing. For example, modal verbs, as engagement resources, are used to mitigate the certainty of a claim (e.g., in expository or argumentative writing) because of limited evidence. Serving as graduation and engagement, respectively, adverbs (e.g., significantly) and research evidence can be used to enhance authorial tone in expository or argumentative writing. Textual meaning is concerned with creating the texture of discourse, responding to the contextual of situational variable-mode (i.e., the channel of the discourse). At the textual level, codes include cohesive ties (e.g., conjunctions or lexical repetition) and thematic progression (e.g., using the ending part of a sentence to start a new sentence and create a linear flow at the discourse level); they highlight how sentences are combined coherently.

Much empirical research that draws on SFL has demonstrated its relationship with students' writing success (e.g., Achugar \& Carpenter, 2012; Mitchell \& Pessoa, 2017). For example, a recent qualitative study by Mitchell and Pessoa (2017) focused on documents written by two novice college writers and interviews in a history class in a Middle Eastern university. Their findings revealed that through exposure to an SFL-based writing workshop, the two college students who had limited writing knowledge were able to orchestrate complex linguistic resources, such as logical relationships at the ideational level, modal verbs, and quotations at the interpersonal level or conjunctions at the textual level, meeting the academic demands of history arguments. As shown above, SFL's perspective on writing not only emphasizes structural accuracy but also highlights how context-specific linguistic choices construct the content of academic writing. It thus optimally aligns with the demands of academic writing. 
However, given the association between students' writing skills and anxiety, it is surprising that no relevant research in the field of SFL has been conducted in this regard. In addition, while SFL-based pedagogy is promising for reducing students' anxiety, learning and teaching cannot be separated from the materials upon which teachers rely to implement their teaching (Tomlinson, 2003). However, learning materials from which SFL knowledge is gleaned seemed to be rarely mentioned in these SFL-based studies. Indeed, these studies focused on co-teaching between SFL experts and subject teachers or SFL experts' professional knowledge while the importance of instructional materials (e.g., textbooks or supplementary textbooks) seemed downplayed (e.g., Mitchell \& Pessoa, 2017). Given the importance of learning materials as a crucial channel for delivering writing knowledge (e.g., SFL), it points to the importance of focusing on the role of material use when investigating the relationship between writing anxiety and students' SFL-based understanding.

\section{Teaching based on online resources}

While the line of research on instructional materials acknowledges the importance of reading material as an important channel for developing a knowledge repertoire, it particularly points out the limited content in traditional textbooks, and suggests the potential of using online resources to supplement in-classroom teaching because of its easy accessibility and multimodal learning platform (Lau et al., 2018; Taffs \& Holt, 2013; Tomlinson, 2003). Unfortunately, the use of online resources for writing instruction is still clustered around teaching vocabulary (e.g., Gilmore, 2008), nurturing students' ideas for academic writing topics (e.g., Sloan, Porter, Robins, \& McCourt, 2014), creating collaborative learning platforms, such as online bulletin boards (e.g., Challob, Bakar, \& Latif, 2016; Ferriman, 2013), or writing structure (Taffs \& Holt, 2013). In other words, these studies on the relationship between online resources and writing are limited to the macro landscape of e-learning resources as regards writing.

Indeed, a paucity of research in the field of online resources-based pedagogy has delved into the knowledge afforded for composing writing. Among them, by emphasizing teachers' mediation, Taffs and Holt's (2013) research touched on the link between online resources and discourse resources, although not in every dimension of linguistic skills. By focusing on second-year undergraduate environmental science students in an Australian university who were mediated in using online resources (e.g., podcasts for constructing their academic writing with regard to how to write a literature review), the study showed that students were able to structure literature and compose content with confidence and less anxiety, along with some linguistic skills (e.g., how to connect ideas and write in a scientific tone). Despite a lack of knowledge of language theory guidelines underlying the mediation-based curriculum, Taffs and Holt's important study sheds light on the inclusion of online resources to alleviate students' writing anxiety by offering them relevant language skills.

As shown above, while highlighting the valuable potential of using online resources through teachers' careful design and implementation, studies on online resources in the writing classroom are still limited, let alone those that specifically focus on reducing writer's anxiety. In the face of the rich content that online resources can potentially provide, including specialized linguistic knowledge needed for writing, Lau et al. (2018) 
noted that there is an urgent need of a framework to use as "a guide for utilizing the different types of e-learning resources and designing the delivery approach" (p. 11). The SFL-based writing instruction, as mentioned in the early section, seems quite compatible with the mediating use of online resources and the urgent need to meet the challenges of academic writing that cause writers' anxiety.

In sum, based on the three lines of reviewed literature, each demonstrates components crucial to students' successful writing. More importantly, there is great potential to connect online resources and SFL-based theory to reduce writers' anxiety. However, no such research has been conducted in this area. To explore students' anxiety reduction in the material-reliant classroom, this study seeks to investigate how the use of online resources informed by SFL impacted student writer's anxiety.

\section{Methodology}

Indeed, given no such research available, the study aims at exploring the relationship between writers' anxiety and pedagogical design of online materials in an English writing classroom. Therefore, it is justifiable in adopting an exploratory case study approach (Merriam, 1998).

\section{Research context}

Derived from a large nationally funded project on college students' writing development, the study was conducted in a weekly expository course (about 95 min each week) over a semester at an urban university in China.

The university is located in the northern part of China and is specialized in foreign language teaching in China. It is especially renowned for its English teaching in China and sets high standards for its students' English language development. At the same time, the university gives teachers freedom to innovate their teaching style to best help students. As such, in the English department of this university where the study was conducted, instructors were encouraged to integrate research with teaching so as to better benefit their students' learning. That is, colleagues in the department often met regularly to discuss issues related to students' language learning, such as their writing anxiety. In the meantime, instructors were also encouraged to conduct research and solve these issues through the methods they felt useful. Overall, the university and its English department created an optimal venue where teachers could empower themselves in innovating their language teaching.

The students were second year English major students who learned and spoke English as a foreign language (EFL). It has to be noted that English major students in the context were trained to develop language proficiency in five literacies (speaking, writing, listening, reading and translation).They spoke Chinese as their mother tongue and came from diverse regions of China. When this study was conducted, they had never been abroad. This means that they learned English in China as EFL students. In particular, the students, while aware of the importance of creating effective writing, were constrained by their rooted knowledge that good writing was nearly equal to structural accuracy or complexity, but had no idea about meeting the demands of academic writing. This was understandable in that students generally wrote essays based on their knowledge received in class; that is, although they came from different regions of 
China, the language teaching they had experienced was focused on the instruction of vocabulary and the accuracy of grammar rather than at the level of discourse, like many other EFL contexts (Zhang, 2017). It was no surprise that at the beginning of the semester the students revealed their writing anxiety, primarily because they had limited knowledge about writing.

The instructor (also the researcher) received his doctoral education in the United States and holds a doctorate degree in linguistics. After graduation, he returned to China to teach college English. Prior to his teaching of academic writing, the instructor conducted a pre-study survey and found that students in his classroom were anxious because of their limited knowledge in constructing writing. Informed by studies on SFL in preparing students for writing success, relevant literature on the dynamic relationship between writing anxiety and the knowledge repertoire, as well as the limited content of mandatory textbooks, the instructor boldly implemented his SFL-based use of online resources in the writing classroom. At the same time, when conducting research, the instructor strictly followed the ethical standards endorsed by the department and university. The online resources were twofold: one was about sample texts (see Zhang, 2018); the other was about the SFL perspective on writing, meaning that students were instructed to read knowledge about SFL's constructs from the online resources and were encouraged to link it to writing samples (see Zhang, 2018). The resources included verbal materials and audio materials that can be accessed on the internet for free. In the process of implementing writing instruction, the teaching included in-class mediation, such as learning SFL-related constructs, using the knowledge to deconstruct samples, and constructing writing together. Meanwhile, the instructor would also draw the SFL knowledge in providing written feedback, though in a thought-provoking way (e.g., Does the choice of participant make senses here? Does the chunk well connect to each other?). The instructor also offered out-of-class mediation across the semester in terms of the link between SFL and academic writing, including teacher-student discussions about academic writing, and written and oral feedback. The out-of-class mediation took place about bi-weekly on an individualized basis, each time lasting about 45 min on average. Over the semester, the students could revise their essays many times until they were to the instructor's satisfaction. In addition, their grade on each essay was based on their final draft so that they would not feel anxious in the process of writing construction.

\section{Participants}

Nineteen students participated in this study. They all consented to be part of the study when the researcher announced the purpose of this study at the beginning of the semester. None of them withdrew when their final grades were posted at the end of the semester. However, four focal students were selected for an in-depth exploration within this case study. The students were selected for several reasons. One is that the four students were similar to other students in the classroom: they were anxious about their writing, and they did not know how to construct their writing effectively, lacking confidence. In addition, the four students were quite willing to share their emotional vexation associated with writing construction. Most importantly, these students had never been exposed to either online resources or SFL's perspective on writing instruction. As 
such, these four students became suitable for exploring the SFL-based use of online resources as well as the changes in their anxiety in the writing classroom. The four female students were Anne, Eva, Mary, and Susan (all pseudonyms).

\section{Data collection and analysis}

The data collected for this study included the following aspects. The students' reflections were one of these. Over the semester, the students were asked to write reflections on their learning experiences with online learning resources that included SFL knowledge and the link with their understanding of writing or writing anxiety. The reflections basically took place twice per month. In addition, semi-structured interviews on an individualized basis over the semester were also collected (see Appendix for sample questions). The reason for choosing individualized interview instead of focus group interview was because participants felt more comfortable to share their thoughts directly with the researcher. Each participant was interviewed roughly every 2 weeks; each time the interview lasted about $30 \mathrm{~min}$. The interviews served to see how the students developed in such a mediated learning context while also helping to clarify or shed further light on their reflections, such as their emotional distress with SFL-based deconstruction of texts with their teacher or on their own. To better capture students' emotions toward writing, in-class interactions were also collected. Most importantly, over the semester, the students' compositions (four essays in total along with their revised versions) were also collected, since they were optimal evidence demonstrating the students' writing knowledge, which could provide useful information on its relationship with their anxiety.

As a case study (Merriam, 1998), data in this study was primarily analyzed inductively and recursively through qualitative content analysis (Neuendorf, 2016). Based on the transcribed data, each data set (e.g., interview transcripts, reflections, and in-class interactions) was initially read many times, guided by the research questions. Based on emergent thematic elements, codes derived from relevant literature in the line of SFL (e.g., the three meanings, contextual variables) and writing anxiety were used to further refine themes generated within each dataset (Bayat, 2014; Huerta et al., 2017; Horwitz, 2001; Mitchell \& Pessoa, 2017). In particular, when tracking the trajectory of students' writing anxiety change over the semester, coders were informed by the definition of writing (i.e., emotional discomfort, such as apprehension and distress, associated with writing) (Huerta et al., 2017). That is, to unearth students' writing anxiety change, verbal or written expressions from their interviews or reflections that showed student writers' emotions in relation to writing were selected and coded (see also MacIntyre \& Gardner, 1988). These expressions could be positive, moderate or negative feelings. For example, in the interview, Eva, at the beginning of the semester, said, "writing is torturing as I do not know how to do it well". The word, "torturing", was coded as a negative feeling and considered as a sign of student writer's high-level anxiety. Similarly, in Susan's reflection written the end of the semester, she noted, "writing makes me feel a sense of achievement, especially after learning SFL". The expression, "a sense of achievement", was coded as a positive feeling and taken as a sign of Susan's reduced anxiety. The change, narrated or written by students, was also thoroughly compared and contrasted with students' writing over the semester to empirically show the 
relationship between students' writing anxiety and their SFL knowledge. In other words, a qualitative analysis was conducted to understand the change of students' writing anxiety. In addition, an SFL-based deductive analysis was conducted on students' writing, focusing on their linguistic repertoires beyond structural accuracy, such as the way they orchestrated the academic tone or combined their ideas (Achugar \& Carpenter, 2012; Schleppegrell, 2007). It was through this iterative process that the themes were unearthed. Meanwhile, field notes made by the instructor in and out of the classroom over the semester were also collected and used to anchor the analysis and validate the findings. To further verify the findings, another qualified researcher also helped review and verify the analysis; any different opinions on the analysis were revisited and discussed until agreement was reached.

\section{Results}

Overall, the students' writing anxiety arose from a constrained learning and teaching context. Through reconstructed learning and teaching communities where online materials were adopted in line with SFL, students were offered a new understanding and expectations of writing at the discourse level. More importantly, along with their SFL knowledge, they gained confidence as authentic writers, who could effectively regulate writing with less anxiety.

\section{Students' initial anxiety with writing and paradoxical confidence as writers}

The students were initially anxious about the writing, although they wanted to be good writers. This seemed related to a lack of knowledge of writing expectations. As Eva and Mary said in their interviews:

Eva: I like writing. .. but I did not know what teachers want from us, and I was not taught so clearly. .. I know the purpose. .. but when it comes to the details, I am not so clear. .. so I write down what is from my mind.

Mary: I wrote grammatically decent sentences. .. but my teachers still said it was not good. .. I am confused. .. and feel stressed. .. what should I do?. .. and they did not give me specific instructions and I really want to be a good writer. I felt lost. .. I really had no idea about how to improve it. .. I rely on my own intuition in making revisions.

The two representative narration segments included the typical expressions about their emotional discomfort that exemplified the four students' high-level writing anxiety at the beginning of the semester, such as "I do not know what teachers expect from us" "I am not so clear", "I am confused" "feel stressed" and "I really had no idea". On the other hand, students also expressed their interest in writing ("I like writing"). Obviously, students still felt motivated to improve their writing. However, due to a lack of explicit guidance on the linguistic intricacies beyond grammar, they could only produce grammatically correct sentences and were anxious about how to meet the demands of academic writing.

Additionally, the students also felt that the materials used for the writing classroom did not provide useful knowledge that could help with their writing. This also made 
them anxious about their writing development. Anne and Eva noted in their reflections and interviews, respectively:

Anne: Textbooks are important learning sources we use in class and out of class. .. but I did not see coherent knowledge covered there. .. I mean the textbook has something there. .. but so random. .. both teachers and the textbook did not offer insightful understanding.

Eva: But what I can read and what I should read. .. I do not think I am well guided. .. how can I improve my writing?. .. This is really stressful for me. We really need additional and well-organized reading resources.

As the main learning resources for students to accumulate writing knowledge, they did not feel helped by their textbooks as they lacked principled knowledge, which was exacerbated by a lack of effective instruction. As such, the students felt additional stress and desired new guidance. Their anxiety in this regard could particularly be illustrated by expressions in the above excerpts, such as "The textbook did not offer insightful understanding", "I did not see coherent knowledge" and "This is really stressful for me".

Interestingly, although the students were not exposed to effective instruction or materials in their previous learning, they seemed confident that they could do better with effective guidance. As Susan said in the interview:

I mean I am not anxious just for the writing itself. .. More precisely, I am anxious about how to compose writing. You see, we can have good grammar... I mean if we were effectively taught, I believe we could also do well with our writing.

That is, the students' writing anxiety was not something innate in them that could not be alleviated. Instead, they were confident about becoming good writers, although their practices were constrained by the teaching and learning resources they had received. Their confidence seemed to stem from their good mastery of grammar, another dimension of English language literacy.

\section{The zigzag path of students' anxiety alleviation in an online resources-based writing classroom}

When attempts were being made to offer students writing knowledge and reduce their anxiety in the sense that SFL-based online resources were used, the students' limited knowledge base (i.e., their established understanding about grammar-based writing) hampered their new knowledge acquisition promoted in the new curriculum. This can be shown in the following out-of-class discussion on Susan's essay:

Teacher: Look at this part? (The teacher was tutoring his students and asking his student to explain the way she composed supporting details for a claim on the difference between college life and high school life.)

Students: What do you mean?

Susan: (No response). 
Teacher: Do you still remember what you studied in class: the connections between sentences?

Susan: Not too clearly. I just made every sentence correct. .. I did not think too much this time...

Teacher: You see. .. exactly. .. but think carefully about the meaning in this local context. .. or the semantic load. .. such as modal verbs.

Susan: Sorry. .. I did not notice that. .. I thought I had checked many times and did a great job. .. because I am not quite clear about that and felt comfortable writing my own way. .. I have never learned this [the interpersonal meaning] before, which is difficult to me.

As shown above, the students initially understood their writing as a grammatical activity as they had been exposed to that mode of teaching for years. As such, they did not feel emotionally comfortable adjusting to a new curriculum that used online resources to push them to write at a discourse level. Instead, it caused them emotional discomfort. As Susan reflected later, "I am confused and felt I had too much to learn. .. I tried but could not do as our teacher showed us in class or what was written in the sample texts." Expressions, like "confused", "too much to learn" and "could not do", conveyed students' high-level anxiety when exposed to SFL in the very beginning.

At the same time, they were also emotionally burdened because of the online materials as learning resources, which was exacerbated by the intensive learning of additional materials. As Anne said in the interview:

In my previous learning course, we never had to learn these [online] materials. .. and write reflections. .. we just wrote and read some sample texts. .. the learning mode is stressful.

Echoing Anne, Mary also noted:

We have lots of course assignments and I had to read this. .. I feel a bit stressed as I have to absorb it within a short time. .. although I did feel learning different knowledge. . .

Expressions, such as "stressful" and "a bit stressed", evidently projected students' anxiety in the writing classroom. That is, their understanding of learning resources was limited to traditional hardcopy textbooks or in-class teaching. The students had never had the learning habit of using online resources and conducting reflective learning on their own within such an intensive time, which caused their additional cognitive load.

The most important emotional distress for these students seemed particularly related to the efforts needed to understand the SFL-related constructs offered by online resources and deconstruct the sample texts on their own following in-class learning. They became more anxious because of the complexity of the knowledge they needed to draw upon. As Eva noted in their interviews, 
I feel learning new knowledge is necessary. .. but I also feel it difficult to thoroughly understand them, such as appraisal. .. and apply them to my writing. .. I understand my teacher's intention is to be good [writers]. .. but I really feel a bit overwhelmed.

Obviously, with their immature awareness of the relationship between writing and SFL-based online resources, the students felt challenged in using the knowledge to improve their writing, causing their anxiety (e.g., "difficult", "a bit overwhelmed"). Their emotional discomfort or anxiety was also enhanced because of constant feedback from the teacher beyond language form. As Susan, later on, reflected:

I wrote based on my intuition. .. when I am corrected. .. I do not feel happy. .. every time the instructor says things not related to grammar. Like my previous teachers, they would just correct grammar and structure or just confusing content. .. I

honestly did not understand why I had to care about so much.

Obviously, the students felt emotionally dis-aligned with the curriculum because of their immature understanding of it. Anxiety in this regard can be illustrated by expressions "I do not feel happy" and "I honestly did not understand why I had to care about so much". This happened in a particularly obvious way during the process when the students submitted their first two essays following written and oral feedback. For example, they often failed to correct colloquial expressions, show the connections between sentences, or provide appropriate engagement or graduate resources to anchor semantic load (field notes). Their stress in resisting correcting feedback was understandable since they had two conflicting perspectives and were not very clear about why their writing should be constructed in this way. Also, adding to their stress was the fact that they had to move out of their comfort zone.

\section{Increased confidence and mitigated anxiety as a result of a further understanding of online resources}

This watershed seemed to occur when they wrote their third essays; at this point, their feeling about writing was becoming positive, and they also started to renew their understanding of writing as a more cultural and contextual activity than its grammar-based counterpart. Furthermore, their frustration with the demands from these online resources seemed to also interact with their determination to be good writers as well as to have confidence in themselves, making them work intensively in and out of class. As Anne reflected:

Although it is challenging. .. we cannot give up. .. Learning anything new is not easy. Learning more means gaining more and more opportunities in and out of campus and to be better writers. .. I believe I can.

In other words, while experiencing challenges, the students did not prolong their anxiety in this regard. Instead, their confidence in themselves (e.g., "we cannot give up", "I believe I can") pushed them to meet these challenges. This was particularly exemplified by their efforts to continue their study after class. As Mary revealed in the interview: 
Out of class, I keep reading these online resources and use the knowledge to do my own analysis in order to understand the secret of sample writings.

Apparently, while bothered by temporary anxiety in this new learning environment, the students empowered themselves agentively to overcome their negative feelings and positively use the online resources to furnish their writing knowledge repertoires because of their understanding of the importance of the new knowledge and the potential gains associated with this.

Meanwhile, teacher mediation in and out of class also played a role in helping the students understand the information contained in the online materials and reduce their anxiety. For example, Susan reflected:

With the constant guidance in and out of class, I feel I now have a relatively clear idea of what these materials are trying to say. .. and feel comfortable with using this knowledge in my writing. .. I mean I have gotten sufficient metalinguistic knowledge from these online materials. .. Now I can better understand what the textbooks are trying to say and how to recheck my own essay before submission.

Students seemed to experience reduced writing anxiety (e.g., "feel comfortable", "better understand"). In other words, in the online resources-based classroom coupled with teacher mediation, the students were gradually supplementing their original writing knowledge, which was constrained by structural rules and caused their emotional difficulties with composing good quality essays. In the process, teacher mediation seemed crucial in helping them overcome difficulties with regard to understanding meta-linguistic knowledge beyond grammar. As a result, they felt much more relaxed and less anxious in the writing classroom.

Indeed, their calm peace of mind as writers emerged particularly along with their growing knowledge at the ideational, interpersonal, and textual levels, all of which apparently transcended their previous knowledge of writing as a grammar-based activity. At the ideational meaning, students came to understand the way of constructing ideational meaning. As Anne reflected: "The new knowledge helped me realize that we have to use explicit logical relationships, and we also we avoid the mental process (e.g., I think), or first-person pronouns as participants when proving supporting details." Anne further said: "with the ideational meaning learned, I can write with less panic". That is, Anne's new knowledge seemed to occur with her alleviated anxiety (i.e., "less panic") and improved confidence with writing construction.

At the interpersonal level, students also experienced similar gains in knowledge and boost in writing confidence. Eva said, "I now see the importance of hiding authorial stance when writing expository writing or adjusting the tone, such as through the use of modal verbs. .. it is different from narrative". Eva's expression, such as "happily able to interact with a large scope of audience" in the interview excerpt below, also demonstrated her reduced anxiety:

While my previous teachers often said my writing was too personal or not objective, they did not tell me why and how to improve it. This had bothered and stressed me. 
.. with the useful knowledge at the interpersonal dimension, I am happily able to interact with a large scope of audience and deliver effective and reliable information.

In a similar vein, the textual dimension also afforded students strategies in coping with writing and dealing with stress. Mary remarked:

I had been told that my writing was too isolated and too loose, like spoken sentences, but I did not know how to do this, except by adding some conjunction words as previously emphasized. Through textual meaning, I see how sentences are connected to make cohesion beyond conjunctions, such as lexical cohesion and thematic progression. This clarifies for me how and why good texts are very unified.

Resonating with her new understanding, Mary also reflected that: "I now feel so happy to know that textual meaning helps me solve the question by offering me the whole landscape of how discourse cohesion works. This makes me feel confident and clear in using them for my own writing". The expressions (e.g., "so happy", "feel confident and clear") well signaled Mary's decreased anxiety as a student writer.

Indeed, by the end of the semester, the students were able to apply the knowledge that was crucial for them to construct effective writing. The knowledge seemed to effectively guide the writing practices that were bothering them and causing their anxiety. It has to be noted that almost minimal feedback was needed for the third and fourth essays as they were ideationally, interpersonally, and textually appropriate. The features of the last two essays emerged along with the first two essays that they were instructed to revise at the end of the semester. Overall, in addition to self-regulation of structural errors, students also exemplified their new knowledge by attending to the relationship between the content and contextually appropriate lexical/grammatical resources.

At the ideational dimension, students showed clear logical relationships and field-specific choices in their last two essays or corrected the inappropriate expressions in their first two essays. For example, Susan used an explicit cause-effect relationship to show her supporting details. Mary also replaced her use of colloquial lexical choices with academic ones and deleted mental processes (i.e., I think) to present fact-like information. At the interpersonal level, the students also demonstrated appropriate interpersonal features in their writing. For example, in the last two essays, Susan utilized modal verbs or quantifiers when providing details, unlike her previous writing whose tone was not appropriate. She also revised her previous two writings in this regard. Eva also learned to employ research evidence with appropriate engagement resources to support details (e.g., according to. ..), especially in her last essay. At the textual level, the students also demonstrated the cohesive mechanism in their writing. For example, Mary used transitional words to create a natural flow between background information and thesis statements she wanted to share with readers in her final two essays. Eva displayed lexical cohesion when presenting information, and she particularly shuffled between synonyms and linear themes to connect meaning in her support. Also, all of the students revised their previous two essays and also projected their knowledge well with regard to textual meaning in the writing. In all, the online resources used and delivered in line with SFL gradually offered students enhanced knowledge on how academic 
English text was composed beyond grammar. As Susan further reflected at the end of the semester:

I feel I can now know how to better appreciate texts, or how to analyze texts. .. if a text is full of grammar mistakes, I can say that it is a bad text. But what if a text is all correct sentences? How I am going to evaluate it? The knowledge provided by these online resources did a great job in clarifying writing in a holistic way. This also clarified and supplemented the knowledge in the textbook or what I have learned. .. this further boosts my confidence with writing construction.

The students apparently gained more confidence in composing writing. This confidence emerged out of their ability to apply newly gained SFL-based knowledge to regulate their own writing. In this sense, the students seemed capable of navigating academic writing in practice, which made them write with ease. This confidence in the actual writing practice was particularly exemplified by their happiness with orchestrating linguistic resources to produce quality writing at the ideational, interpersonal, and textual levels. In other words, the linguistic knowledge offered from online resources was mapped from their understanding to their actual practices, serving as a cementing tool to afford students confidence and alleviate their writing anxiety to a greater extent.

\section{Discussions and implications}

This case study investigated the impact of SFL-based online resources on students' anxiety associated with writing construction. The study aligned itself with those that showed a negative linear relationship between students' writing knowledge and their writing anxiety (e.g., Cheng, 2002). Overall, it yields the following findings.

First, by understanding students' anxiety as levels of emotional discomfort (Huerta et al., 2017), the study contributed to existing research on reducing students' writing anxiety by developing students' SFL-based knowledge via online resources. Particularly, through prolonged exposure to SFL-based online resources, the students started to replace their knowledge of writing, which was centered on grammar knowledge, with writing as a contextually embedded activity. This made them relatively comfortably engage in writing construction. In this sense, this study further showed the usefulness of online resources as learning materials in delivering knowledge in the writing classroom (Lau et al., 2018; Sloan et al., 2014; Tomlinson, 2003). More importantly, among studies exploring students' anxiety in the writing classroom (e.g., Cheng, 2002; Huerta et al., 2017; Taffs \& Holt, 2013; Zhang \& Rahimi, 2014), they were focused on the description and analysis of student writers' anxiety. Even among studies that tried to mitigate student writers' anxiety through providing writing knowledge, they either focused merely on furnishing students with knowledge on the structure of writing, such as sentence accuracy in traditional classrooms (e.g., Bayat, 2014) or only limited dimensions of language knowledge beyond structure, such as nurturing students' ideas for academic writing topics (e.g., Sloan et al., 2014). Nevertheless, the current study showed that adopting online resources that included authentic writing knowledge (i.e., SFL) was helpful in reducing their writing anxiety. This study, through its careful design and delivery of online resources and through demystification of academic writing at various levels in line with SFL, is in sharp contrast with relevant previous studies where limited 
efforts were made to reduce students' anxiety either in the traditional classroom or an online resources-based classroom.

In addition, students' writing anxiety was particularly pacified at the level of three dimensions of meaning/content within the paradigm of SFL provided by online resources, although such anxiety alleviation seemed subject to a spiral development. Indeed, students had to battle with their previous knowledge and construct their new knowledge before understanding how SFL plays out in writing, which caused their additional anxiety. However, their anxiety was externally alleviated by teachers who assisted students in orchestrating SFL knowledge in relation to writing (c.f., Bayat, 2014; Horwitz, 2001) as well as their self-agency in synergizing with teacher support to transform themselves into less anxious writers on the journey of writing development (c.f.). Particularly, in the process of acting upon their hard-learned writing knowledge, the students gradually demonstrated their confidence and motivation in constructing efficient writing at the level of ideational meaning, textual meaning, and interpersonal meaning, such as their maneuvering of logical relationships, academic tone, or discourse coherence through culturally and linguistically appropriate resources. Additionally, this part of the findings further enhanced our understanding about the usefulness of SFL, especially in tandem with online resources, which differs from previous research. Indeed, previous SFL-based research was focused on the impact of SFL experts' pedagogical knowledge on students' writing development and ignored the materials used in the writing classroom and students' emotional trajectory (e.g., Mitchell \& Pessoa, 2017).

Nevertheless, limitations of this study have also to be acknowledged. As a case study, caution must be taken when generalizing its findings, as they may only be applicable to similar EFL contexts. In addition, as a case study limited to one semester of learning expository writing, information regarding how students emotionally reacted to the new genre of writing was not clear when exiting the classroom after this semester. Future studies could be conducted in a longitudinal mode or English as a second language contexts so as to track changes in students' writing anxiety when interacting with diverse writing genres (e.g., argumentative or research papers for a particular disciplines), since each genre of essay also has its own unique features, making it worthy of further exploration. Most importantly, in the process of exploring the relationship between students' writing anxiety and SFL-based knowledge gained from online resources, other factors might also play out. For example, students were given sufficient time, which might also reduce their anxiety. Future research could adopt quantitative analysis and investigate the relationship among multiple variables.

The implications of this study include the following dimensions. First, given the close relationship between students' anxiety and linguistic knowledge, it is possible that teachers create mediating learning contexts in the classroom, either between teachers and students or among students. Indeed, students' writing anxiety is also related to their learning difficulties in the process of an anxiety-reduction-centered classroom. By doing so, students would feel more comfortable in approximating core knowledge to construct effective essays and become less anxious when independently composing essays. The mediating strategies could include teachers' use of plain language or students' first language if English is not their first language (Yu, 2013) or creating multimodal learning contexts (audio, visual mode) so as to make students understand the required 
writing knowledge and reduce their relevant anxiety. Second, given that textbooks may be limited in their contents, it would be optimal for educators to include online resources as additional learning materials. In particular, their use has to be informed by a useful learning theory in order to meet students' needs and anxieties (such as speaking or reading). Third, the teacher's pedagogical knowledge of a certain subject is crucial for using the material, offering students' useful knowledge, and reducing their anxiety. Given the multiple layers of SFL theory, it looks promising for administrators to promote SFL-based teacher training for teachers at various levels in the field of English language teaching. In doing so they can use the knowledge and offer students' effective knowledge to demystify academic literacy and learn with confidence.

\section{Appendix}

Sample interview questions

1. How do you feel about your writing in the past semesters?

2. What makes feel so?

3. What is your understanding of SFL so far?

4. What do you think of SFL in relation to writing construction?

5. Have you experienced any changes in your feelings with writing so far?

\section{Acknowledgements}

The author would like to thank participants who were involved in the study.

Funding

The project is funded by National Social Science Foundation of China (17CYY019).

Availability of data and materials

Data and material can be available on request.

Author's contribution

The paper was finished solely by the author. The author read and approved the final manuscript.

Competing interests

The author declares that he has no competing interests.

\section{Publisher's Note}

Springer Nature remains neutral with regard to jurisdictional claims in published maps and institutional affiliations.

Received: 23 January 2019 Accepted: 30 April 2019

Published online: 30 May 2019

References

Achugar, M., \& Carpenter, B. D. (2012). Developing disciplinary literacy in a multilingual history classroom. Linguistics and Education, 23(3), 262-276.

Bawarshi, A. S., \& Reiff, M. J. (2010). Genre: An introduction to history, theory, research, and pedagogy. West Lafayette: Parlor Press.

Bayat, N. (2014). The effect of the process writing approach on writing success and anxiety. Educational Sciences: Theory and Practice, 14(3), 1133-1141.

Challob, A. A. I., Bakar, N. A., \& Latif, H. (2016). Collaborative blended learning writing environment: Effects on EFL students' writing apprehension and writing performance. English Language Teaching, 9(6), 229-241.

Cheng, Y. S. (2002). Factors associated with foreign language writing anxiety. Foreign Language Annals, 35(6), 647-656.

Ferriman, N. (2013). The impact of blended e-learning on undergraduate academic essay writing in English (L2). Computers \& Education, 60(1), 243-253.

Gilmore, A. (2008). Using online corpora to develop students' writing skills. ELT Journal, 63(4), 363-372.

Halliday, M. A. K., \& Matthiessen, C. M. I. M. (2004). An introduction to functional grammar. London: Edward Arnold.

Horwitz, E. (2001). Language anxiety and achievement. Annual Review of Applied Linguistics, 21, 112-126.

Huerta, M., Goodson, P., Beigi, M., \& Chlup, D. (2017). Graduate students as academic writers: Writing anxiety, self-efficacy and emotional intelligence. Higher Education Research \& Development, 36(4), 716-729.

Hyland, K. (2007). Genre pedagogy: Language, literacy and L2 writing instruction. Journal of Second Language Writing, 16(3), 148-164. 
Lau, K. H., Lam, T., Kam, B. H., Nkhoma, M., Richardson, J., \& Thomas, S. (2018). The role of textbook learning resources in elearning: A taxonomic study. Computers \& Education, 118, 10-24.

Maclntyre, P. D., Gardner, R. C. (1988). The measurement of anxiety and applications to second language learning: An annotated bibliography. (ERIC Document Reproduction Service No. ED 301 040)

Martin, J. R., \& David, R. (2008). Genre relations: Mapping culture. London/Oakville: Equinox.

Merriam, S. B. (1998). Qualitative research and case study applications in education, (2nd ed., ). San Francisco: Jossey-Bass.

Mitchell, T. D., \& Pessoa, S. (2017). Scaffolding the writing development of the argument genre in history: The case of two novice writers. Journal of English for Academic Purposes, 30, 26-37.

Neuendorf, K. A. (2016). The content analysis guidebook. Thousand Oaks: Sage.

Schleppegrell, M. J. (2007). The meaning of grammar. Research in the Teaching of English, 42, 121-128.

Sloan, D., Porter, E., Robins, K., \& McCourt, K. (2014). Using e-learning to support international students' dissertation preparation. Education+Training, 56(2/3), 122-140.

Taffs, K. H., \& Holt, J. I. (2013). Investigating student use and value of e-learning resources to develop academic writing within the discipline of environmental science. Journal of Geography in Higher Education, 37(4), 500-514.

Tomlinson, B. (2003). Developing materials for language teaching. London: Continuum.

You, X. (2004). "The choice made from no choice": English writing instruction in a Chinese university. Journal of Second Language Writing, 13(2), 97-110.

Yu, S. (2013). Teacher feedback and peer feedback: An activity theoretical perspective. Modern Foreign Languages, 36(1), 70-76. Zhang, X. (2017). Understanding Chinese EFL teachers' beliefs and practices in the textbook-based classroom. Bern: Peter Lang.

Zhang, X. (2018). Mitigating suburban English writing teachers' constrained professional development through distance education: One case study. The International Review of Research in Open and Distributed Learning, 19(5), 238-254.

Zhang, L. J., \& Rahimi, M. (2014). EFL learners' anxiety level and their beliefs about corrective feedback in oral communication classes. System, 42, 429-439.

\section{Submit your manuscript to a SpringerOpen ${ }^{\circ}$ journal and benefit from:}

- Convenient online submission

- Rigorous peer review

- Open access: articles freely available online

- High visibility within the field

- Retaining the copyright to your article

Submit your next manuscript at $\boldsymbol{\nabla}$ springeropen.com 